Revista Estudios, (37), 2018.

Diciembre 2018-Mayo 2019

ISSN 1659-3316

Saborit Valdes Kirenia

IV Sección: Sociedad, vida política e historia

\title{
Una mirada al sujeto político desde la Antropología Filosófica: Diversidad y prácticas políticas
}

\author{
Kirenia Caridad Saborit Valdes \\ Universidad de Camagüey, Cuba \\ kirenia.saborit@reduc.edu.cu \\ https://orcid.org/0000-0002-4251-9877
}

Recibido: 6 de junio de 2018

Aceptado: 20 de setiembre de 2018

Resumen: El artículo refiere a una de las problemáticas que afronta el escenario latinoamericano actual, el papel del sujeto político en la construcción de espacios y proyectos nacionales en un contexto sociocultural marcado por políticas diversas. Como la participación del hombre - tanto individual como en colectividad - en el campo de la política guarda relación con factores culturales, étnicos, demográficos, económicos, sociopolíticos, de género en general, el objetivo de este trabajo es, valorar el papel que desempeñan diversos sujetos políticos desde una visión de la Antropología Filosófica en la actualidad. La revisión bibliográfica, el método histórico-lógico y el análisis documental permiten constata que, la problemática objeto de estudio resulta importante en el proceso de transformación política que viven los países. Se ofrecen análisis críticos que ayudan a repensar al sujeto político en su propio proceso de reconstrucción de sí mismo con sus características identitarias y culturales.

Palabras clave: actores políticos; sujeto político; antropología; antropología filosófica; prácticas políticas.

\section{Look the political subject from the philosophical anthropology: Diversity and political practical}

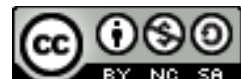

La Revista Estudios es editada por la Universidad de Costa Rica y se distribuye bajo una Licencia Creative Commons Atribución-NoComercial-CompartirIgual 3.0 Costa Rica. Para más información envíe un mensaje a revistaestudios.eeg@ucr.ac.cr. 
Abstract: The article refers to one of the problems facing the current Latin American scenario, the role of the political subject in the construction of national spaces and projects in a socio-cultural context marked by different policies. As the participation of man - both individually and collectively - in the field of politics is related to cultural, ethnic, demographic, economic, sociopolitical, gender in general, the objective of this work is to assess the role played by various political subjects from a Philosophical Anthropology vision at present. The bibliographical revision, the historical-logical method and the documentary analysis allow verifies that, the problematic object of study is important in the process of political transformation that the countries live. Critical analyzes are offered that help to rethink the political subject in his own process of reconstruction of himself with his identity and cultural characteristics.

Keywords: political actors; political subject; anthropology; Philosophical Anthropology; political practices

\section{Introducción}

Los profundos cambios y transformaciones que ocurren en el mundo contemporáneo en el orden político, económico, cultural, ideológico incluso científico-tecnológico - con diversas consecuencias para la raza humana - traen consigo la presencia de actores y fuerzas políticas que proyectan una acción en la gama de espectros que envuelven a las sociedades. De ahí que, la búsqueda de soluciones a situaciones diversas principalmente en la arena política, genera la emergencia del llamado sujeto político. Estos para Paredes (2009) son "(...) un tipo de sujetos sociales que despliegan su voluntad colectiva en base a acciones de politicidad, (...) en forma tal de presentar alternativas con un contenido emancipatorio, cuestionando/rupturando/modificando las relaciones de poder existentes." (p. 91-92)

La importancia que adquieren los diversos sujetos políticos en las sociedades contemporáneas es objeto de estudio de diversos especialistas. Lo corroboran los trabajos de Paredes (2009), Retamozo (2010), Méndez (2011), Zemelman (2011), Díaz (2012), Agier (2012), López (2013), Martínez (2014), Samaddar (2014) y

\section{(C) $(00$}

La Revista Estudios es editada por la Universidad de Costa Rica y se distribuye bajo una Licencia Creative Commons Atribución-NoComercial-CompartirIgual 3.0 Costa Rica. Para más información envíe un mensaje a revistaestudios.eeg@ucr.ac.cr. 
Accossatto (2017); los que constituyen las bases teórico-metodológicas de los análisis que se realizan sobre la significación y pertinencia de los mismos.

Diversas experiencias en el contexto global y de manera particular en América Latina muestran una pluralidad de sujetos políticos cuyos desempeños en la conformación de espacios políticos por un orden social más justo, no puede obviarse. Ejemplo de ello son: movimientos sociales, indígenas, feministas, juveniles, sindicatos, clase obrera, campesinos, pueblo como conglomeración homogénea, líderes, partidos políticos y otras formas sociales que, persiguen distintos objetivos pero, tienen en común la aspiración a una mejor inserción en la sociedad desde prácticas políticas que le permitan involucrarse, tomar partido, ser parte importante del cambio social en fin, constituirse para sí porque se preocupan por su destino.

Frente a esta postura Muñoz (2014) afirma que,

"El hombre es un ser de relaciones en contextos, por ende es un ser histórico encarnado en cada historia y civilización de los diferentes pueblos. Comprender antropológicamente al ser humano como ser de relaciones, nos ubica en la perspectiva filosófica de reconocer la historia de la especie humana y la biografía de cada ser en particular, como un proceso de humanización, en el cual el ser, en sus relaciones, posibilita la vinculación y la transformación social." (p. 193).

En este análisis, el autor presenta al hombre como punto de partida de toda actividad humana, como el problema central de toda existencia en los distintos órdenes de la vida.

Como los procesos sociopolíticos que se viven en la región muestran una complejidad dada por el lugar donde se desarrollan, los sujetos que los protagonizan, sus características culturales así como la variedad de componentes identitarios y nacionales, en este trabajo se realiza una valoración del papel que desempeñan distintos sujetos políticos desde una visión de la Antropología Filosófica.

\section{(c) (i) (9) (2)}

La Revista Estudios es editada por la Universidad de Costa Rica y se distribuye bajo una Licencia Creative Commons Atribución-NoComercial-CompartirIgual 3.0 Costa Rica. Para más información envíe un mensaje a revistaestudios.eeg@ucr.ac.cr. 
Los principios y fundamentos de la Antropología Filosófica constituyen sustento metodológico de las ideas que se presentan en esta investigación al considerar que, en el centro del desarrollo histórico social se encuentra la actividad prácticotransformadora del hombre que deviene cada vez más en un estadío superior con respecto a períodos precedentes, lo que lleva a su constitución como un sujeto político.

Tiene un lugar especial para la Antropología Filosófica la comprensión del ser del hombre y su lugar en la sociedad a partir de estudios de la modernidad que, vislumbran nuevos conocimientos, prácticas sobre el hombre y sus entornos sociales, culturales, naturales asociados a la sociedad civil y política. Los estudios antropológicos filosóficos aspiran a obtener nuevos análisis a partir de situar en el punto de mirada del hombre su acción política. Así, se ofrecen valoraciones desde este sustrato - sobre el hombre como sujeto activo, creador, cuyas manifestaciones en la sociedad son resultados de sus óptimas capacidades, portador de una diversidad cultural de acuerdo a su época histórica.

En conclusión, los actores y fuerzas políticas que participan en el espectro sociopolítico se proyectan una participación activa, capacidad transformadora de la realidad que les toca vivir, siendo el hombre factor esencial desde una dimensión integral y holística y es, punto de partida para el conocimiento de sí y del mundo en general.

\section{Antropología Filosófica y sujetos políticos.}

La Antropología Filosófica brinda la posibilidad de ver al hombre desde todos los aspectos de la existencia humana desde una visión del pasado, presente y futuro, unido a su actividad social, política, económica, sus producciones materiales y espirituales y toda la obra cuanto puede crear, así como con sus relaciones con otros hombres pues, este refiere a una complejidad de formas sociales y culturales. Afirma Rivera (2010) que, "(...) da cuenta de una realidad donde

La Revista Estudios es editada por la Universidad de Costa Rica y se distribuye bajo una Licencia Creative Commons Atribución-NoComercial-CompartirIgual 3.0 Costa Rica. Para más información envíe un mensaje a revistaestudios.eeg@ucr.ac.cr. 
"coexisten en paralelo múltiples diferencias culturales, que no se funden, sino que antagonizan o se complementan"' (p.7).

Por ello, en el desarrollo histórico social que vive la humanidad desde sus inicios hasta nuestros días, el hombre - como sujeto social - tiene un lugar primordial, sobre todo en el proceso de producción y reproducción de la vida tanto física, cultural, material y espiritual. En dicho proceso, éste se transforma en sujeto de cambio dentro de la dinámica de los distintos sujetos que conforman su espacio. Al plantear de la Antropología Filosófica, el hombre explica todas las funciones y actividades desde un enfoque integral que lo hace protagonista en el decursar de su tiempo.

En tal sentido, se destacan los aportes de la Antropología Filosófica desde las diversas teorías sobre las personas, el individuo o los sujetos. De ahí que, la autora de esta investigación acude a recursos de la Antropología Filosófica, esenciales para el análisis a realizar. Puede citarse: características biológicas, culturales unidas a normas y valores morales de las cuales son portadoras los hombres, la dimensión ética y social presente en la interpretación de la práctica del hombre, su subjetividad porque la persona remite a particularidades antropológicas filosóficas: un espacio, una sociedad y una cultura.

En consecuencia con ello, resulta necesario comprender las realidades, contextos y experiencias para entender la razón de ser del hombre. Los atributos que Méndez (2011) le asigna al lugar donde se desarrolla el dinamismo humano no deben ser soslayados. Para el autor, el espacio político constituido por este sujeto a través del discurso, gestos, actos, así como la actuación de la "(...) universalidad más allá de su contingencia, en vistas de aparecer en un mundo nuevamente relacionado, a pesar de no haber sido contados como existentes." (p. 57), muestra la necesidad de pensar el sujeto político en condiciones de transformación, actualización y producción.

\section{(c) (i) (2)}

La Revista Estudios es editada por la Universidad de Costa Rica y se distribuye bajo una Licencia Creative Commons Atribución-NoComercial-CompartirIgual 3.0 Costa Rica. Para más información envíe un mensaje a revistaestudios.eeg@ucr.ac.cr. 
Las diferentes teorías sobre los sujetos políticos requieren ser repensadas a la luz de los procesos sociopolíticos más actuales en América Latina para llegar a conformar una plataforma de la realidad que viven los pueblos en cuanto a la disputa por un orden social justo, la complejidad de conflictos que se suceden en los sistemas políticos, la lucha por una representación en los sistemas gubernamentales y las aspiraciones por un poder público que verdaderamente responda a necesidades y demandas de la sociedad.

En consecuencia con ello, la Antropología Filosófica ofrece elementos para un análisis del pensamiento crítico de las realidades latinoamericanas, especialmente en la reflexión en torno a la acción y proyecciones de los sujetos políticos. Tales recursos la autora de este trabajo los resume en:

- Toda forma o práctica humana debe ser estudiada en su totalidad, integralmente y como centro de atención de ella, el hombre con toda la complejidad que este implica desde el ser hasta su esencia biológica y cultural más específica.

- La dimensión filosófica no debe ser desdeñada en el análisis de un proceso sociohistórico, político, cultural, etc. pues el hombre, como ser complejo es portador de una amplia gama de factores biológicos, culturales y sociales.

- El hombre como ser social históricamente determinado se vuelve capaz de asumir la historia de la humanidad pensada en términos de desarrollo, progreso, conflictos, emancipación.

- Los diferentes espacios de configuración y reconstrucción del ser social están asociados a desarrollo, conciencia, organización social, economía, política, pero sobre todo a semejanzas y diferencias culturales en una misma realidad o región; todo lo cual ayuda a entender al hombre en todos sus comportamientos.

A tenor con lo anterior, la problemática del sujeto político resulta ser una cuestión de interés desde una visión de la Antropología Filosófica. Este se descubre como 
un sujeto social, histórico concreto, capaz de llevar adelante procesos que destacan su vida pública. A partir de lo cual y desde la experiencia vivida en algunos países de la región - en la actualidad - puede afirmarse que importantes reivindicaciones son lideradas por movimientos sociales y particularmente por el movimiento indígena, el cual conduce una lucha que tiene como prioridad las libertades políticas individuales y colectivas y la satisfacción de necesidades sociales, políticas, gubernamentales con búsqueda de representatividad en este espectro. Como expresa Agier (2012) “(...) este sujeto debe crear el momento político para transformar el escenario humanitario reinante y convertirlo en un "escenario democrático" (...)” (p. 21).

Las diferentes manifestaciones de lucha que muestran hoy muchos sujetos políticos ya sea constituidos como partidos políticos, grupos sociales, organizaciones u otras formas sociales son expresión de una voluntad de participar con ideas y propuestas propias, que responden en gran medida a tradiciones de lucha en torno a las relaciones de poder y la propia política. En dicha práctica se conjugan valores, sentimientos, emociones, sensaciones de los hombres, lo cual no escapa a una mirada antropológica.

Los proyectos políticos de los sujetos políticos en la región expresan abiertamente la eliminación de formas de exclusión, la participación ciudadana como un derecho natural, el involucramiento popular en la toma de decisiones políticas y la defensa de los derechos y deberes del hombre en las distintas sociedades. Todo lo anterior no solo es contenido de la democracia que se defiende o que otros pretenden constituir es además, parte importante de lo que algunos autores llaman la revolución democrática y cultural; como una de las maneras de hacer política y de superar los viejos vestigios de dominación y hegemonía colonial. Desde esta perspectiva cobran importancia aquellos presupuestos de la Antropología Filosófica que refieren al desarrollo, estructura, características de la cultura humana y que ayudan a dirigir la sociedad hacia una transformación social. 
Ante los innumerables cambios, avances y a la vez contradicciones que existen en las sociedades de la región latinoamericana los sujetos políticos deben asumir el rol de protagonistas y sintiéndose objetos y sujetos de la realidad, proyectarse como actores o fuerzas políticas posibles de revolucionar cada realidad. En el proceso de construcción de cada una de las sociedades predominan los patrones de conducta, estilos de vida, estereotipos en las prácticas políticas. Siguiendo los criterios de Agier (2012) sobre los sujetos, este “(..) aparece como un (...) más cercano a situaciones en las que las personas toman la palabra, la política, la estética... más cercado, en fin, al accionar. El sujeto surge entonces en situación (...)" (p. 22).

Como parte de las realidades del sujeto político está su subjetividad, la que se construye en un contexto social muy específico que tiene expresión en su pensamiento y se encuentra vinculada a las relaciones prácticas, comunicativas y socializadoras. En este orden expone Díaz (2012) que,

"(...) la emergencia de subjetividad, no es un hecho genético, por el contrario, es un acontecimiento socio-cultural (...) en él, juegan un papel importante como dispositivos que potencian ciertos sentidos subjetivos, los procesos de socialización, vehiculizados en las agencias socializadoras y encarnados en los agentes socializadores respectivos" (p. 59).

Ello conduce a pensar al sujeto político desde sus manifestaciones afectivas, conscientes, en un sistema de relaciones humanas que desde fundamentos filosóficos encuentra lugar en el reconocimiento a la razón humana, la liberación, el decoro del hombre, la autonomía para establecer sus relaciones con el resto mundo exterior.

La conformación de una subjetividad del sujeto político pasa entonces por, la resignificación de un pensamiento libertador, su enmarcación y concientización en torno a los procesos que percibe y la experiencia acumulada en el decursar del tiempo. Las contribuciones de Accossatto (2017) en torno a la subjetividad del 
individuo así lo corroboran, "(...) el comienzo de cualquier experiencia humana que busca su dignificación, se vincula con la emergencia de una subjetividad política necesaria para la realización de cualquier acción colectiva" (p. 220).

Un sujeto político significativo en la región lo constituyen los partidos políticos, sobre todo, aquellos que permanecen proponiendo programas y proyectos representativos de las necesidades y aspiraciones de las distintas clases de la sociedad. Estas organizaciones representativas del orden político y social se reconstruyen colectivamente sin perder de vista que cada hombre de manera individual responde a sus necesidades materiales, prácticas culturales, hábitos de vida que se conjugan en intereses colectivos. Este es el reto más inmediato que a entender de la autora, tienen por delante los partidos políticos en el continente, reconstruirse colectivamente para sí, en representación de intereses y deseos comunes.

En este orden señala Muñoz (2016) que, “(...) luchas históricas que se han dado en colectivos con capacidad de instalar en la agenda pública demandas novedosas, creando un "consenso crítico" y restando, muchas veces, obediencia al poder instituido." (p. 98), son un desafío que debe sistematizarse. A ello se agrega que, los colectivos implican un sistema de relaciones, espacios y tiempos que los hacen complejos pero a la vez distintivos y variables.

En el mismo orden, se considera que ciudadanos con alto grado de participación en las cuestiones políticas y en la vida pública se experimentan como fuerzas políticas de trascendental importancia incluso, pueden constituirse como alianzas políticas para proyectar acciones de politicidad y transformación social. En este caso, capas y sectores sociales como: profesionales, estudiantes, intelectuales, trabajadores, buscan una inserción en la sociedad para mostrar experiencias resultantes de las condiciones políticas y económicas, reivindicaciones y valores sociales, conscientes de su realidad.

\section{(c) (i) (2)}

La Revista Estudios es editada por la Universidad de Costa Rica y se distribuye bajo una Licencia Creative Commons Atribución-NoComercial-CompartirIgual 3.0 Costa Rica. Para más información envíe un mensaje a revistaestudios.eeg@ucr.ac.cr. 
La Antropología Filosófica viene a afianzar la idea de que, el hombre, con capacidad transformadora recibe de la sociedad y de las distintas formas de estratificación social existentes las influencias posibles, establece relaciones complejas por ser el hombre un ente de la comunidad social y el medio físico y ambiental. Con énfasis en ello, Morales (2003) señala que, para “(...) el hombre (...) la ciudadanía es justamente la condición trascendental de posibilidad de su propia afirmación y construcción como humano lo cual no ocurre sino, justamente, como ciudadano (...)". (p. 59). Estos sujetos políticos, ciudadano o sujetos de la política experimentan las distintas experiencias de otros hombres y las inquietudes hacia alcanzar beneficios colectivos.

El sujeto político, entendido como un hombre de valores, convicciones, ideales, de posición activa ante la vida, con capacidad autocrítica, se encamina hoy hacia la constitución de una ciudadanía, una identidad nacional, cuan complejas resulten ser sus interrelaciones con componentes, factores o sujetos de su entorno social. Zemelman (2011) defiende que,

“(...) no es posible pensar en ningún tipo de estructura social, económica o política, como tampoco cultural, si no es como resultado de la presencia de sujetos en complejas relaciones recíprocas en cuanto a tiempos y espacios; lo que implica tener que enfocar los procesos como construcciones que se van dando al compás de la capacidad de despliegue de los sujetos (...)" (p. 2).

Las ideas que sostienen diversos autores sobre el papel de la clase obrera internacional y particularmente en América Latina reafirman que esta se convierte en sujeto político especialmente en sujeto de diversas manifestaciones de lucha, la que adquiere un marcado carácter popular, cuyos objetivos específicos se dirigen fundamentalmente a la liberación de la dependencia económica y alcanzar crear espacios alternativos.

Por ello es de interés destacar que, en la región se avanza mucho en la incorporación de la clase obrera a la emancipación social y se ve favorecida en 
algunos países donde alcanzan a acceder al empoderamiento local, a participar en los principales requerimientos de las políticas públicas, a tomar partido en los procesos electorales en fin, a participar en la política.

En Venezuela, la participación política de la clase obrera y trabajadora se encamina desde la llegada al poder político del presidente Hugo Rafael Chávez Frías - incluso sigue siendo actualidad una proyección - a la recomposición del movimiento sindical, cuya representación se concibe desde el Ministerio del Poder Popular para las Comunas, instancia donde se acometieron acciones para mejorar las condiciones de trabajo de las personas y satisfacción de necesidades materiales como: aumentos salariales, mejoras de vida, asignación de derechos y deberes. Hoy, dicha participación se dirige a la gestión de nueva fuerza laboral, a crear las bases para reasignación de espacios laborales, de estudio, a la producción de bienes materiales y servicios, al involucramiento en la toma de decisiones políticas y tiene máxima expresión en la lucha contra la guerra económica de las oligarquías neoliberales. En este proceso se consolidación la cooperación y dada las circunstancias, se busca reconstituir la clase obrera y trabajadora como un nuevo sujeto político que logre la sostenibilidad del país y la estabilidad política.

Lo anterior confirma las bases alternativas que se buscan para lograr establecer un paradigma latinoamericano de inclusión sociopolítica para las clases y capas de la sociedad con especial cooperación de la clase obrera. Esto sucede porque al plantear de Morales (2003), las reflexiones sobre el hombre se hacen desde la propia historia en relación con el progreso, conflictos, emancipaciones, revoluciones; se convierte así en objeto de toda valoración humana.

En el marco de este análisis se involucran los llamados movimientos sociales los que, manifiestan una dinámica en la acción política que los lleva a la solución de conflictos, se constituyen como formas de resistencia y luchan ante las políticas neoliberales por el rescate de intereses e identidades nacionales.

\section{(c) (i) (2)}

La Revista Estudios es editada por la Universidad de Costa Rica y se distribuye bajo una Licencia Creative Commons Atribución-NoComercial-CompartirIgual 3.0 Costa Rica. Para más información envíe un mensaje a revistaestudios.eeg@ucr.ac.cr. 
Para Accossatto (2017), una de los paradigmas más recurrentes en la actualidad a que aspiran distintos movimientos sociales $u$ otras formas de organización es la búsqueda de reivindicaciones y mecanismos de participación política que conduzcan a "vías de politización, multiplicando y extendiendo su capacidad de representación: movimientos indígenas y campesinos, urbanos territoriales y socio-ambientales, colectivos feministas (...), organizaciones culturales y de derechos humanos, agrupaciones de trabajadores/as desocupados/as y fábricas recuperadas, etcétera" (p. 215).

Los movimientos sociales en la conformación de sus estrategias políticas se acompañan de lo popular, lo democrático y lo colectivo con una fuerte incidencia en lo social para transformar valores, identidades y culturas que manifiestan historicidad, acción política y relaciones espaciales para la construcción de una alternativa de cambio.

El Congreso de los Pueblos en Colombia - por citar un ejemplo - se constituye como actor social y sujeto político conformado por movimientos sociales en un proceso convocado por el movimiento indígena. Cuyo reconocimiento es evidente dada la efectividad de las luchas y la permanencia en la movilización política. Dicho movimiento tiene una identificación con lo popular donde, enfatiza Ortiz (2016), se “(...) identifican organizaciones campesinas, indígenas, de comunidades negras, barriales, sindicales, de pensionados, de mujeres, de diversidad sexual, grupos juveniles y colectivos artísticos, grupos eclesiales de base, colectivos ecologistas, agencias de prensa alternativa y colectivos de educación popular.” (p. 3). Ello, en la representación de identidades colectivas populares.

Para este autor, la colectividad es condición indispensable en la acción política y la emergencia de un horizonte de emancipación al considerar, el papel del hombre desde una forma de organización colectiva para hacer la política. Es a partir de esta condición que surgen formas de resistencia y descolonización también, la

\section{(c) (i) (2)}

La Revista Estudios es editada por la Universidad de Costa Rica y se distribuye bajo una Licencia Creative Commons Atribución-NoComercial-CompartirIgual 3.0 Costa Rica. Para más información envíe un mensaje a revistaestudios.eeg@ucr.ac.cr. 
constitución de nuevas identidades políticas y rearticulación de acciones colectivas de sujetos oprimidos.

Importantes procesos de articulación nacional se desarrollan en Bolivia, Ecuador y México donde movimientos indígenas protagonizan acciones de inclusión, reivindicativas y valores en la construcción de valores colectivos. Se proyectan demandas, propuestas y prácticas políticas que tienen como objetivo el empoderamiento popular y la formulación de soluciones a las exigencias y denuncias que se hacen. Lo popular adquiere importancia no solo por la implicación de sectores, capas y clases sociales que se configuran en la base de una sociedad sino, porque dan respuestas a condicionantes sociales que resuelven conflictos, dilemas e intereses. Volviendo a los criterios de Morales (2016), desde la sociedad moderna los sujetos que se configuran con plena participación en las cuestiones políticas, se constituyen como sujetos políticos, alcanzan a ser una fuerza política en tanto se emancipan políticamente para involucrase en la gestión pública.

Otro sujeto político importante en la construcción de una sociedad más justa lo es el campesinado. En Cuba, alcanza una condición distintiva desde el derecho a la tierra, experimenta profundas transformaciones que son máxima expresión del establecimiento de la propiedad social. Como sujetos políticos de cambio, los campesinos se identifican como una fuerza organizada que lidera la lucha contra las ineficiencias en el sector agrícola y proponen solución a demandas económicas en el país para la sostenibilidad alimentaria. Una de las prácticas de esta clase como sujeto político es la búsqueda incesante de nuevos mecanismos de producción que contribuyan a la satisfacción de necesidades materiales de la población y que enaltezcan el modelo económico con altos índices de productividad. Aún, se trabaja la búsqueda de alternativas económicas que permitan mejorar la calidad, eficiencia y eficacia de la producción en el campo.

El Movimiento de Trabajadores sin Tierra de Brasil como sujeto político es paradigma en Latinoamérica con objetivos que se enmarcan en: la lucha por la 
tierra, la reforma agraria y la transformación social en general. Entre las características que se derivan de su acción está la construcción de prácticas representativas y organizadas, que persiguen cambiar la sociedad en la que viven cotidianamente. Por ello, se expande a los espacios que abarcan los llamados nuevos movimientos sociales: educación, comunicación, vivienda, trabajo, salud. En un estudio sistematizado por Wrobel (2015) sobre este movimiento se reconoce en la vida cotidiana la premura de los cambios políticos., "(...) hay una clara conciencia de que, en última instancia, la tierra para las familias campesinas y la Reforma Agraria no podrán ser alcanzadas sin una transformación política profunda" (p. 95).

Las diversas comunidades de la región Latinoamericana o los pueblos organizados se configuran como sujetos políticos. La identidad de los pueblo parte de su propia autonomía y conciencia nacional relacionada con hábitos, costumbres, tradiciones, estilos de vida que le imprimen al hombre la experiencia y capacidad de acción y procesos identitarios. Acota Muñoz (2016) que "El "pueblo" (a veces articulado a la democracia, otras no tanto) emergió como un exceso incontenible dentro de las coordenadas que organizaban la vida política frente a los que se presentaban como los verdaderos propietarios del poder de decisión vinculante" (p. 98).

Los pueblos entran en el escenario político en la disputa por la renovación de nuevos órdenes de dominación, donde pretenden articular proyectos de resistencias política, de lucha ideológica, instauración de una gobernabilidad estable y de alcance de objetivos democráticos en sus estructuras organizativas. De ahí, la necesidad de llegar a formarse como un sujeto político capaz de desplegarse con ideas y propuestas propias, de forma colectiva, en las decisiones que afectan a la sociedad.

Los llamados sindicatos o centrales de trabajadores también desempeñan un papel significativo en la vida política y pública. Aunque muchas de las prácticas se limitan a reformas económicas y demandas para mejoras salariales o condiciones 
de trabajo, enfrentan en la actualidad las políticas de privatización neoliberales y su lucha tiene fuerte base de desarrollo en la sociedad civil. Un aspecto de singular importancia en este proceso es que, la acción de los sindicatos en la arena política permite ganar espacio público para la instauración de determinadas políticas estatales: trabajo decoroso, acceso a políticas públicas, el uso público de recursos naturales, el derecho a la tierra, entre otros.

En efecto, las bases teóricas de los autores citados hasta este momento ubican en el centro de toda reflexión el ser humano, por lo que asume desde la Antropología Filosófica una posición humanista como base integradora de toda posición y apreciación crítica. El ser humano, es tomado en cuenta como un sujeto de la historia, capaz por sí mismo de hacer su propia vida. En tanto, todo sujeto social deviene en sujeto político a partir de tradición histórica y con las herencias culturales que le corresponde de todos los seres humanos que le anteceden.

Desde esta misma perspectiva, la sistematización de los referentes teóricos estudiados permiten subrayar la condición humanista del hombre como aspecto esencial de lo propiamente humano, cuestión que interpreta en la vida política y social de las personas. Al respecto es necesario reflexionar porque, para los autores, las luchas políticas del hombre están asociadas a su propia existencia.

No obstante, en la región los distintos sujetos políticos aún no alcanzan todas sus aspiraciones, preocupaciones, necesidades y demandas, como tampoco se solventan todos los problemas relativos a la intervención en las decisiones más importantes sobre los destinos políticos de los países. Entran entonces los desafíos que más apremian y los retos que en lo adelante los distintos sujetos políticos en la región deberán emprender para llegar a conformar un espectro político de cambio. Se destacan los siguientes elementos:

- Romper con los esquemas de sociedad y sistema político donde los distintos actores $u$ fuerzas políticas existentes participen en ordenamiento público, en la generalización de políticas públicas populares.

\section{(c) (i)(2) (2)}

La Revista Estudios es editada por la Universidad de Costa Rica y se distribuye bajo una Licencia Creative Commons Atribución-NoComercial-CompartirIgual 3.0 Costa Rica. Para más información envíe un mensaje a revistaestudios.eeg@ucr.ac.cr. 
- Establecer oportunamente el discurso político, las dinámicas grupales como espacios de comprensión, de inteorización y concientización de realidades para crear conciencia de la importancia de defender la participación ciudadana.

- Involucrarse decisivamente en la toma de decisiones políticas desde una implicación individual y colectiva que incluya a movimientos sociales, clase obrera y otros actores políticos desde la política para construir una fuerza social alternativa.

- Crear nuevas políticas a la altura de los sujetos y actores sociales de estos tiempos, que permitan la articulación colectiva de todas las fuerzas verdaderamente transformadoras del cambio social.

- Reconstituir nuevos sujetos políticos capaces de enfrentar las nuevas luchas sociales de los nuevos tiempos.

En este caso, señala Salazar (2013) que

"Para poder sembrar los reclamos, es necesario pasar por un proceso de articulación con otras fuerzas y segmentos políticos, con el propósito de jerarquizar las distintas y variadas demandas, ordenar la escala de metas, nutrir las exigencias de carácter transversal que movilizan grandes sectores y sean abarcativas a nivel nacional; también, asignar los tiempos políticos de cada una de ellas, donde la articulación no quite a las contiendas particulares su carácter, sino que las dimensione y fije en escenarios amplios y convergentes y estos anclajes vayan abriendo nuevos espacios de lucha. (p. 1)

Debe destacarse que, en el proceso de nuevas alternativas, proyectos, programas, reivindicaciones del sujeto político latinoamericano - sea individual o colectivo - subyacen características biológicas, culturales propias de cada hombre que entraran en contradicción con las determinadas prácticas políticas de una manera $u$ otra pues, cada individuo es portador de un constructo cultural del cual no puede este desprenderse tan fácilmente. Al tratar de la constitución de un sujeto político se da paso a un extenso y complejo proceso de experiencias

\section{(c) (i) (2)}

La Revista Estudios es editada por la Universidad de Costa Rica y se distribuye bajo una Licencia Creative Commons Atribución-NoComercial-CompartirIgual 3.0 Costa Rica. Para más información envíe un mensaje a revistaestudios.eeg@ucr.ac.cr. 
vividas, los dinamismos socioculturales que se dan en contextos son parte de una realidad y abarcan una variedad de espectros sociales.

Aunque diversos autores desde la Antropología Filosófica reconocen que las formas más altas de la vida humana está dada en contextos, algunos insisten en señalar que el sujeto se configura a través de sus construcciones culturales en situaciones históricas, políticas, sociales y culturales desde donde brindan la posibilidad expresar el sentido de la vida.

De ahí que, los diversos sujetos políticos en Latinoamérica hoy, se diferencien del resto de los actores sociales por su propósito y práctica de intervención pública, su tarea de contribuir decisivamente a la creación de nuevos proyectos individuales y colectivos que son parte de su actuar cotidiano. Así, estos se encaminan a trascender las actividades que en campo social responde meramente a subsistir o a hacer resistencia frente a los problemas de las políticas económicas y culturales.

Los sujetos políticos deben definir claramente sus roles en el proceso de desarrollo social y político y articular con mejores condiciones con el resto de los sujetos o formas sociales de organización para alcanzar un bien común. La constitución de tales aspiraciones está estrechamente asociada a la capacidad de los sujetos políticos para definir los espacios de su actuación política que deben pretender desarrollar en su accionar político. Como sustenta (Paredes 2009) “(...) los sujetos políticos presentan ciertos elementos constituyentes que le permiten desplegar su politicidad, estos son: la identificación antagónica, la voluntad colectiva transformacional, las acciones rebeldes y los proyectos emancipatorios" (p. 93).

La realidad latinoamericana actual continúa incorporando a sectores poblacionales, organizaciones políticas, sociales y de masas, distintas clases sociales, a afirmarse y distinguirse como verdaderos sujetos políticos, a constituirse como sujetos de resistencia a escala global. Actores, fuerzas políticas o sujetos están en la reconstrucción de alianzas estratégicas destinadas a 
configurar un programa de lucha nacional en consonancia con las aspiraciones de la región, en correspondencia con intereses de las sociedades que desean la construcción de nuevos proyectos de vida más justos, equitativos y democráticos. Es en este punto donde la Antropología Filosófica cobra importancia, donde ve al hombre en su complejidad constructiva de valores, principios, identidades culturales.

La necesidad de que los sujetos políticos en la región continúen aliándose entre ellos mismos es condición indispensable para transitar a nuevas formas de lucha política e ideológica y una garantía para seguir ejecutando cambios sociales que beneficien a la mayor parte de la sociedad. Razón por la que, Martínez (2014) señala en relación al papel que desempeña los sujetos políticos y sus formas de articulación,

"La condición de sujeto político, la condición de experiencia de vida de sujeto político crea un lenguaje, un modo de simbolización. El saber nacido de la experiencia de vida se simboliza, mostrando los hallazgos en el camino recorrido, pero también lo que todavía se desconoce (...)" (p. 1).

Por ello, hoy se continúan redefiniendo nuevos sujetos políticos con un grado de madurez diferente y con necesidades de construcción de lo social y de lo político diferentes a etapas anteriores, donde juegan un papel fundamental los actores políticos capaces de analizar cada realidad local, inaugurando una nueva práctica participativa hacia lo inexplorado. 


\section{Conclusiones}

La cuestión del sujeto político encuentra en la Antropología Filosófica un lugar esencial pues, desde esta perspectiva estos, como actores históricos que articulan relaciones temporales y espaciales definen el curso del desarrollo social, proyectan identidades culturales a partir de cada realidad. Ello lleva a repensar el papel que desempeñan distintos sujetos políticos vinculados a factores tan abarcadores como las dimensiones biológica, cultural y social.

América Latina en la actualidad es escenario donde se construyen y reconstruyen distintos sujetos políticos que asumen posturas políticas radicales, en la defensa de un proyecto de lucha, de resistencia, de reivindicaciones en distintas localidades. Tal construcción de demandas sociales y la configuración de culturas autónomas, crean un marco propicio para el pleno desarrollo de estos, conformados como actores políticos. Es por ello necesario volver a pensar al sujeto político desde la Antropología Filosófica, para integrar a su análisis factores posibles de la vida humana tanto como: política, económica, diversidad cultural.

La pluralidad de sujetos en los países de la región latinoamericana desde las últimas décadas del siglo $\mathrm{XX}$ y hasta la actualidad, reaparece con un marcado contenido político. Las proyecciones, perspectivas y posiciones asumidas en el ejercicio de la política llevan a pensar la elaboración de demandas sociopolíticas, la formación de identidades nacionales y la aparición de conflictos en el marco de las sociedades, caracterizadas por la incidencia de las políticas neoliberales y la crisis estructural que vive el sistema internacional actual, de ahí el punto de partida de esta investigación. 


\section{Bibliografía}

- Accossatto, R. (2017). Sujetos políticos, dignidad y movilización. Aportes de Arturo Roig al estudio latinoamericano de los movimientos sociales y las identidades políticas. Revista de Ciencias Sociales, 4, (7),213-234.

- Agier, M. (2012). Pensar el sujeto, descentrar la antropología. Revista Cuadernos de Antropología Social 35,9-27.

- Balibar, E. (2014). Ciudadano Sujeto. Ensayos de Antropología Filosófica. España: Ed. Prometeo.

- Díaz, A. (2012). Devenir subjetividad política: un punto de referencia sobre el sujeto político. Disertación doctoral publicada, Universidad de Manizales. Manizales, Colombia.

- Gramaglia, P. (2014). Nuevas manifestaciones para nuevas formas de autonomía de los sujetos políticos. Recuperado el 9 de junio de 2018 de, http://web.isanet.org/Web/Conferences/FLACSOISA\%20BuenosAires\%201 4/Archive/74a93afb-323b-43f5-afe5-a39dc7ecff72.pdf

- López, A. (2013). Spinoza: Razón y Poder. Un estudio sobre el sujeto ético y político en Spinoza. Disertación doctoral publicada en Filosofía. Universidad Nacional de Educación a Distancia, Madrid, España.

- Martínez (2014). Apuntes alrededor de la idea del sujeto político. Recuperado el 24 de julio de 2018 de, http://www.congresoed.org/wpcontent/uploads/2014/10/Documento base Jaume.pdf

- Méndez, E.E. (2011). Sujeto político y política. Elementos para una ampliación de la mirada en torno a la constitución del sujeto y el espacio político. Tesis de Magíster en Filosofía con mención en Axiología y Filosofía Política, Universidad de Chile, Santiago, Chile.

- Morales, G. (2003). Cosmopolítica: la política y la antropología filosófica como fuentes mutuas. Revista Ciencias Políticas y Sociales, 196,55-61.

\footnotetext{
(c) (i) (9) (2)

La Revista Estudios es editada por la Universidad de Costa Rica y se distribuye bajo una Licencia Creative Commons Atribución-NoComercial-CompartirIgual 3.0 Costa Rica. Para más información envíe un mensaje a revistaestudios.eeg@ucr.ac.cr.
} 
- Muñoz, D.A. (2014). Antropología filosófica relacional en la obra de Paulo Freire: diálogos con la teoría crítica de Karl Marx. Revista Perseitas, 2, (2), 186-203.

- Muñoz, M.A. (2016). Sujeto político, democracia y pueblo: Argentina y Bolivia frente al nuevo siglo. Revista Entramado, 24,96-110.

- Ortiz, A.M. (2016). El proceso de articulación y constitución del Congreso de los Pueblos como sujeto político en Colombia. (1ra.ed). Buenos Aires: Ed. CLACSO.

- Paredes, J.P. (2009). Constitución de sujetos políticos: elementos epistémicos y metodológicos para su estudio. Tesis de Magister publicada, Universidad Alberto Hurtado, Chile.

- Retamozo, M. (2010). Sujetos políticos: teoría y epistemología. Revista Ciencia Ergo Sum, 18, 81-89.

- Rivera, S. (2010). Ch’ixinakax utxiwa. Una reflexión sobre prácticas y discursos descolonizadores. Buenos Aires: Ed. Tinta Limón

- Salazar, R. (2013). La construcción del nuevo sujeto político en América Latina. Estrategia para buscar la emancipación desde lo popular en el siglo XXI. Recuperado el 25 de julio de 2018 de, http://www.scielo.org.mx/scielo.php?script=sci arttext\&pid=S1665$\underline{05652013000200006}$

- Samaddar, R. (2014). La emergencia del sujeto político. (Trads., C. Juaneda y J.M. Reynares). [s.n.]. (Trabajo original publicado en 2009).

- Wrobel, I. (2015). EI MST de Brasil y la construcción de un sistema educativo autogestionado. Revista de la Red Intercátedras de Historia de América Latina Contemporánea. 2, (3), 93-105.

- Zemelman, H. (2011). Sujeto y subjetividad: la problemática de las alternativas como construcción posible. Revista Polis de Chile, 27,2-9.

\footnotetext{
(c) (i) (2)

La Revista Estudios es editada por la Universidad de Costa Rica y se distribuye bajo una Licencia Creative Commons Atribución-NoComercial-CompartirIgual 3.0 Costa Rica. Para más información envíe un mensaje a revistaestudios.eeg@ucr.ac.cr.
} 